\title{
Mandibular Radiomorphometric Measurements as Indicators of Possible Osteoporosis in Celiac Patients
}

\author{
Hisham I. Othman, $\mathrm{PhD}$, and Suliman A. Ouda, $\mathrm{PhD}$ \\ Department of Oral Basic and Clinical Sciences, \\ Faculty of Dentistry, King Abdulaziz University \\ Jeddah, Saudi Arabia \\ hothman@kau.edu.sa
}

\begin{abstract}
Dual X-ray absorptiometry is the common technique to determine bone mineral density. Because of high costs and limited availability, it is worthwhile to look for alternative diagnostic techniques. The objective of this study was to investigate the use of panoramic radiographs measurements as a predictor for bone mineral density and to identify the subjects with osteoporosis and the increased risk of osteoporotic fractures in celiac patients. The sample of this study consisted of 60 celiac patients ( 36 males and 24 females) aged 22 to 46 years. All patients were diagnosed with celiac diseases, according to criteria of European Society of Gastroenterology. bone mineral density values were measured by Dual Xray absorptiometry equipment at the lumbar spine and were categorized according to World Health Organization classification. Panoramic radiographs were obtained at the same time for all celiac patients providing two essential measurements; mental index and panoramic index. It was found that the mental index and panoramic index measurements were significantly related to bone mineral density measured by Dual X-ray absorptiometry and therefore could be used as diagnostic indicators of mandibular bone mineral density and play a significant role in celiac patient screening for osteoporosis.
\end{abstract}

Keywords: Panoramic radiograph, Osteoporosis, Celiac disease.

\footnotetext{
Correspondence \& reprint request to: $\quad$ Prof. Hisham I. Othman

P.O. Box 80209, Jeddah 21589, Saudi Arabia

Accepted for publication: 24 March 2010. Received: 01 February 2010.
} 


\section{Introduction}

Celiac disease (CD) is an autoimmune disorder caused by wheat gluten and related cereal peptides in genetically predisposed individuals ${ }^{[1]}$. It is characterized by small intestinal mucosal inflammation, villous atrophy and crypt hyperplasia, which will improve with a gluten-free diet. Extraintestinal manifestations such as dermatitis herpetiforms and osteoporosis are common in $\mathrm{CD}^{[2,3]}$. Oral involvement consists of celiactype dental enamel defects in permanent teeth of $50-80 \%$ of adult patients $^{[4,5]}$, and mucosal inflammatory changes including recurrent aphthous ulcers and angular chelitis ${ }^{[6]}$. Celiac disease has been found in at least 3\% of patients suffering from osteoporosis. Osteoporosis affects the craniofacial and oral structures with the same rate as the total body, plus it has been found to be connected with periodontal bone and tooth loss ${ }^{[7,8]}$. There is a positive correlation between the number of teeth and bone mineral density (BMD) at spine and hip ${ }^{[9,10]}$.

In many phases of dentistry, healthy bone with a normal regenerative capacity is essential for a successful outcome. It is important to know the quantity and quality of bone in the jaws when planning prosthetic and periodontal surgical treatment ${ }^{[11]}$. Osteoporosis is defined as "a disease characterized by low bone mass and micro-architectural deterioration of bone tissue, leading to enhanced bone fragility and a consequent increase in fracture risk and pain ${ }^{[12]}$. Furthermore, osteoporosis has been associated in some studies with residual ridge resorption and periodontal bone loss, while bone quality (of which bone mineral density is likely to be a determinant) is of relevance to the success of dental implants ${ }^{[13,14]}$.

BMD at specific sites can be measured using a variety of techniques, including single photon absorptiometry (SPA), dual photon or dual energy X-ray absorptiometry (DPA or DXA) and quantitative computed tomography $(\mathrm{QCT})^{115]}$. DXA is well established as a means of bone densitometry in the spine and femoral neck. It has a high precision and accuracy and is recognized as the best available technique for in vivo bone mass measurement ${ }^{[16]}$.

Radiographic bone density can be assess from simple radiographs in two main ways: by taking linear measurements (morphometric analysis) or by measuring the optical density and comparing it with a step wedge (densometric analysis). Morphometric analysis has been limited to 
cortical thickness measurements at various sites ${ }^{[17-20]}$ and calculation of the panoramic mandibular index ${ }^{[21,22] \text {. }}$

Dental panoramic radiography accounts for $32 \%$ of all medical radiologic examinations in the United Kingdom, with approximately 2 million panoramic radiographs taken annually in National Health Service dental practices in England and Wales alone ${ }^{[23]}$. It has been proposed that osteopenia observed on panoramic radiographs could be used as a referral criterion for BMD assessment ${ }^{[24,25]}$. For this to be a valid method, the first requirement is that mandibular BMD should predictably reflect that of the hip and other important skeletal sites. Osteopenia can be identified by thinning of the cortex at the lower border of the mandible. A number of mandibular cortical indices have been developed to allow quantification of mandibular bone mass and identification of osteopenia $^{[26]}$. Qualitative and quantitative panoramic indices, including the mandibular cortical index (MCI), mental index (MI) or panoramic mandibular index (PMI) have also been used for panoramic radiographs to assess the bone quality and to observe signs of resumption and osteoporosis.

\section{Objectives}

The aims of this study were:

- To assess the relationship between radiomorphometric measurement made from dental.

- Panoramic radiograph and BMD of the lumbar spine measured using dual energy X-ray absorptiometry analysis (DXA).

- To determine whether these radiographic measurements have validity in predicting BMD in celiac patients.

\section{Materials and Methods}

\section{Study Sample}

The sample of this study comprised of 60 celiac patients (36 males and 24 females). The age range was 22 to 46 years. All patients were diagnosed with celiac diseases according to criteria of European Society of Gastroenterology ${ }^{[27]}$. The participants in the study were attending King Abdulaziz University Hospital for follow-up and management of the disease. All patients were on a diet control (gluten free diet). 
Permission was sought from the patients to carry out bone densitometry as a part of study. Local ethics committee approval was gained for the project and the informed consent was obtained from all patients.

An inclusion criterion for all study participants was possession of normal dentition with no dental prosthesis in the mouth. Exclusion criteria included: use of tobacco or medications that affect bone metabolism, presence of metabolic bone disease, cancer with bone metastasis, hyperparathyroidism, leukemia, and multiple myeloma. In addition, the use of glucocorticoid therapy for more than 3 months, significant renal impairment, liver disorder, and osseous lesions in the mandible, non-vertebral osteoporotic fractures or vertebral osteoporotic fracture on X-ray at the time of assessment.

\section{Bone Mineral Density (BMD) DXA Examination}

BMD at the lumbar spine was measured for all patients by dual energy X-ray absorptiometry (DXA) (General Electric, Prodigy, USA) (Fig. 1). BMD values were categorized as normal (T-score greater than $1.0)$ and as indicative of combined osteopenia and osteoporosis (-1 to lesser than -2.5$)$, according to the WHO classification ${ }^{[28]}$. The celiac patients were classified into two groups; low skeletal BMD group if they were osteopenic or osteoporotic and normal group. Reference population data for BMD were provided by the scanner manufacture ${ }^{[28]}$.

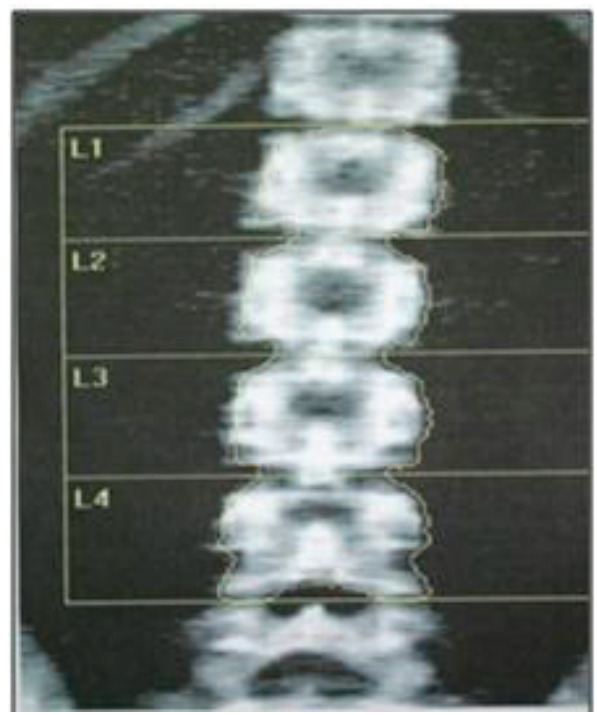

Fig. 1. DXA scan at the lumbar spine. 


\section{Dental Panoramic Examination}

Panoramic radiographs were obtained for all patients at the time of BMD assessment with a Cranex Tome extraoral panoramic X-ray unit (Soredex, Helsinki, Finland) at $12 \mathrm{~mA}$ and $15 \mathrm{~s}$; the kilovoltage varied between 70 and $80 \mathrm{kv}$. Patients were positioned on the panoramic unit in a way that the vertical line produced by the unit was aligned with the facial midline and the horizontal line (Frankfort plane) was parallel to the floor. Film density, patient positioning and head alignment were within the reviewer's standard range of quality.

\section{Dental Panoramic Measurements}

Two essential radiographic measurements were carried out by a radiologist with more than 10 years experience. Readings were carried out twice a month and the inherent magnification of $20 \%$ was subtracted from all readings. Mental index (MI) is the measurement of the cortical width at the mental foramen region on the dental panoramic radiographs as described by Ledgerton et al. ${ }^{[29]}$. A line passing through the middle of the mental foramen and perpendicular to the tangent to the lower border was drawn on the radiograph. Measurements of the lower border cortical thickness were made along this line, using a digital caliper (error factor 0.0002). Panoramic mandibular index (PMI), as described by Benson et $a l .{ }^{[30]}$ as a measure of mandibular osteoporosis represents the ratio of the thickness of the mandibular cortex to the distance between the inferior borders of the mental foramen to mandibular cortex (Fig. 2). Using the same line as described above bilaterally for measuring the (PMI) and the mean PMI calculated for each subject.

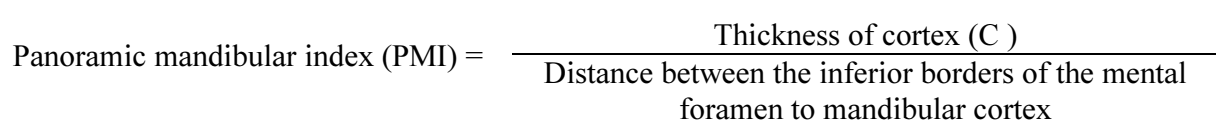

\section{Statistical Analysis}

The relationship between spines BMD derived by DXA and the radiographic measurements (MI and $\mathrm{PMI}$ ) was assessed by calculation of Pearson's correlation coefficients using SPSS PC ${ }^{[31-33]}$ with significant set at $\mathrm{P}<0.05$ level. The means of variables were compared with two tailed "student's" $t$ test. 


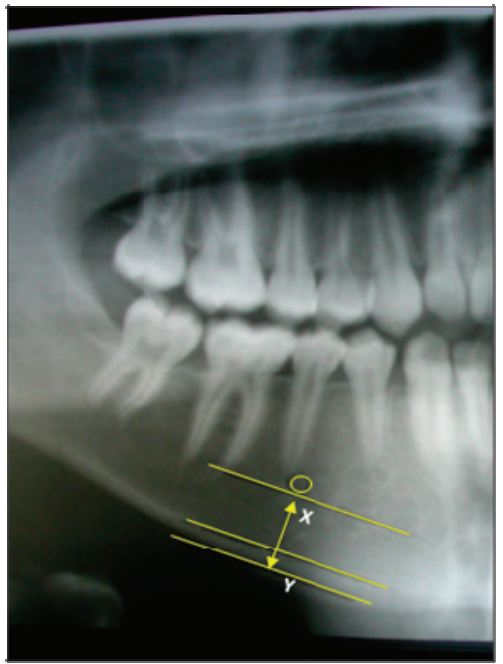

Fig. 2. A cropped panoramic radiograph showing the left body of mandible in the region of the mental foramen $(M)$. A line $(X)$ was drawn from the midpoint of the foramen to the lower border of the mandible, at right angles to the tangent $(Y)$ to the lower border at this point. The width of the cortical bone at the lower border was measured along line $(X)$ from the lower mandibular border to the inner edge of the cortex.

\section{Results}

60 patients were classified according to DAX scan results into two groups (normal and low BMD) on the basis of $\mathrm{T}$ score. There were no significant differences between both groups regarding gender and age.

\section{DXA Examinations}

DXA scan is shown in Table 1. The mean BMD of normal group was $1.04 \pm 0.02$ and for low BMD group was $0.79 \pm 0.16$. The difference between the two groups was statistically significant (Table 1).

\section{Radiographic Measurements}

Mental Index (MI): The mean value of MI measurements of normal BMD group was $4.04 \pm 0.29$ and for low BMD group was $2.97 \pm 0.34$ showing a significant difference between them

Panoramic mandibular index (PMI): The mean value of PMI of normal BMD group was $0.37 \pm 0.03$ and for low BMD group was $0.27 \pm 0.03$ showing also a significant difference (Table 1). 
Table 1. DXA and radiographic measurements values in both groups of celiac patients.

\begin{tabular}{c|c|c|c}
\hline Value* $^{*}$ & Normal BMD $\uparrow(\mathbf{n}=\mathbf{4 2})$ & Low BMD $(\mathbf{n = 1 8})$ & P-Value \\
\hline DXA & $1.04 \pm 0.02$ & $0.79 \pm 0.16$ & 0.00 \\
\hline MI & $4.04 \pm 0.29$ & $2.97 \pm 0.34$ & 0.00 \\
\hline PMI & $0.37 \pm 0.03$ & $0.27 \pm 0.03$ & 0.00 \\
\hline
\end{tabular}

* Mean \pm SD: Significance value $\mathrm{p} \leq 0.05$.

$\dagger$ BMD: Bone mineral density at lumbar spine

The differences of DXA, MI and PMI between males and females for normal and low BMD groups were statistically insignificant (Table 2).

In Table 3, it shows that MI and PMI were positively correlated with DXA scan regarding bone mineral density.

Table 2. Relationship between DXA values and radiographic measurements.

\begin{tabular}{|c|c|c|c|c|c|}
\hline Group & & V & Gender & Mean \pm SD & P-Value \\
\hline \multirow{6}{*}{$\begin{array}{l}\text { Low } \\
\text { BMD }\end{array}$} & \multirow{2}{*}{ MI } & 26 & $\mathrm{M}$ & $2.95 \pm 0.35$ & \multirow{2}{*}{0.77} \\
\hline & & 16 & F & $3.00 \pm 0.35$ & \\
\hline & \multirow{2}{*}{ PMI } & 26 & M & $0.27 \pm 0.03$ & \multirow{2}{*}{0.61} \\
\hline & & 16 & F & $0.28 \pm 0.03$ & \\
\hline & \multirow{2}{*}{ DXA } & 26 & M & $0.79 \pm 0.13$ & \multirow{2}{*}{0.93} \\
\hline & & 16 & $\mathrm{~F}$ & $0.79 \pm 0.20$ & \\
\hline \multirow{6}{*}{$\begin{array}{l}\text { Normal } \\
\text { BMD }\end{array}$} & \multirow{2}{*}{ MI } & 10 & M & $4.06 \pm 0.39$ & \multirow{2}{*}{0.87} \\
\hline & & 8 & F & $4.02 \pm 0.15$ & \\
\hline & \multirow{2}{*}{ PMI } & 10 & M & $0.38 \pm 0.02$ & \multirow{2}{*}{0.38} \\
\hline & & 8 & $\mathrm{~F}$ & $0.36 \pm 0.04$ & \\
\hline & \multirow{2}{*}{ DXA } & 10 & M & $1.04 \pm 0.02$ & \multirow{2}{*}{0.16} \\
\hline & & 8 & $\mathrm{~F}$ & $1.06 \pm 0.2$ & \\
\hline
\end{tabular}

Significance value $\mathrm{p} \leq 0.05$

Table 3. Pearson's correlations between DXA and radiographic measurements in celiac patients.

\begin{tabular}{l|l|c|c|c}
\hline \multicolumn{1}{c|}{ Index } & \multicolumn{2}{c|}{ MI } & PMI & DXA \\
\hline MI & Pearson's correlation & 1 & .938 & .784 \\
\hline PMI & Pearson's correlation & .938 & 1 & .776 \\
\hline DXA & Pearson's correlation & .784 & .776 & 1 \\
\hline
\end{tabular}




\section{Discussion}

The present study suggests that, on average, celiac patients have reduced mineral density at the lumbar spine. This was in accordance with McFarlane et al. ${ }^{[34,35]}$ and Butcher et al. ${ }^{[36]}$ as they found reduced bone mineral density (BMD) at both the spine and hip in celiac patients when compared with age- and gender-matched controls. Celiac disease has been found in at least $3 \%$ of patients suffering from osteoporosis ${ }^{[37]}$.

The pathogenesis of osteoporosis associate with celiac disease is not well understood. It is unclear whether bone loss results from inadequate bone formation or from excessive bone resorption. At diagnosis, the celiac patients frequently have intestinal calcium malabsorption, and hypocalciuria appears to indicate the presence of calcium deficiency. This is accompanied by a relative increase in plasma alkaline phosphatase $\mathrm{e}^{[38-40]}$. Deficiency of vitamin D and secondary hyperparathyroidism are common in newly diagnosed celiac patients and in those with refractory celiac disease, but are less common in patients who respond to a gluten-free diet ${ }^{[41]}$. There is now substantial evidence that celiac disease is associated with infertility in both men and women. In women, celiac disease can lead to amenorrhea and early menopause ${ }^{[42]}$, which are associated with high risk for osteoporosis.

BMD is the ratio of the measured bone mineral content (BMC) in grams divided by the measured two-dimensional projected area in $\mathrm{cm}^{2}$ of the bone(s) being measured; thus the units of BMD are $\mathrm{g} / \mathrm{cm}^{2}$. However, most clinical decisions are based on the T-score, which is calculated by comparing the patient's BMD with the mean value for young normal individuals and expressing the difference as a standard deviation (SD) score $^{[43]}$.

The oral cavity and jaws are radiographically examined more often than any other part of the human body. Panoramic radiograph could be useful as a simple screening method in the diagnosis of osteoporosis and can provide valuable information on the quality of the jaw bone. Osteoporosis can be diagnosed by observing tooth loss, thinning of the mandibular inferior cortex and changes in the morphology of the endosteal margin of the cortex and of the spongy bone of the jaws ${ }^{[16]}$. Mandibular bone mass was correlated with overall skeletal bone mass in many studies ${ }^{[44]}$. 
It had been found in this study that when the value of bone mineral density at the lumbar spine measured by DXA scan was decreased. The PMI was diminished to a point of statistical significance. It means that when the level of PMI decreases, it indicates lowing of bone mineral density. This is in agreement with Bollen et al. ${ }^{[45]}$, they reported that patients with history of osteoporotic changes show increased resorption and thinning of the mandibular cortex. Also MI was correlated with the $\mathrm{t}$-score of lumbar spine. This in accordance with Delvin and Horner ${ }^{[16]}$ and Klemetti et $a l .{ }^{[20]}$ which reported a positive relationship between mandibular cortical thickness and BMD as measured by DXA scan. However, other studies have failed to prove that a significant difference in mandibular cortical thickness exists between osteoporotic and control subjects $^{[46]}$. This conflict may be attributed to the difference in the age groups and referral criteria in their studies. Mohajery and Brooks ${ }^{[47]}$ compared the thickness of the mandibular cortex and the lamina dura of the tooth socket in normal and osteoporotic women. There were no significant differences in any of the mandibular measurements and there was no correlation between skeletal and mandibular bone measurements.

Panoramic radiography is frequently use for the diagnosis of disease affecting the teeth and jaws in general dental practice ${ }^{[48,49]}$. The incidental findings detected on panoramic radiographs can be performed for the identification of women who have no awareness of their low BMD and who could benefit from BMD testing. Dispersion of information on the prevention of osteoporosis has produced a strong public drive towards implementation of the proper means to minimize the process of bone reduction ${ }^{[50]}$. There have been reports linking osteoporosis to alternations of the trabeculae displayed on dental radiographs. These finding suggests that dental radiographs may serve a useful role in screening patients for osteoporosis. Because radiographic assessment of bone mineral density and bone height are of great value in planning further dental treatment; panoramic or periapical radiographs are routinely made before treatment planning ${ }^{[51,52]}$. In the contrary, it had been demonstrated that the sensitivity and specificity for using panoramic radiographic measurements do not lend themselves to satisfactory diagnosis of osteopenia and osteoporosis. Instead, these measurements might be useful as a method of risk assessment when combined with other factors ${ }^{[53,54]}$. 
Further researches and studies on a larger patient sample are required for comparing the diagnostic validity of radiographic measurements with other referral criteria (family history, clinical risk factors), and to determine whether combinations of positive clinical and radiographic criteria add to validity.

\section{Conclusion}

Because of high costs and limited availability of DXA equipment it is worthwhile to look for alternative diagnostic techniques for osteoporosis. Panoramic radiographs constitute an integral part of almost every routine dental evaluation and can be useful for the early diagnosis of osteoporosis in celiac patients. Dentists have sufficient clinical and radiographic information that enables them to play a significant role in patient screening for osteoporosis.

\section{References}

[1] Mäki M, Collin P. Coeliac disease. Lancet 1997; 349(9067): 1755-1759.

[2] Corazza GR, Di Sario A, Cecchetti L, Tarozzi C, Corrao G, Bernardi M, Gasbarrini G. Bone mass and metabolism in patients with celiac disease. Gastroenterology 1995; 109(1): 122-128.

[3] Collin P, Reunala T, Rasmussen M, Kyrönpalo S, Pehkonen E, Laippala P, Mäki M. High incidence and prevalence of adult coeliac disease. Augmented diagnostic approach. Scand J Gastroenterol 1997; 32(11): 1129-1133.

[4] Aine L, Mäki M, Collin P, Keyriläinen O. Dental enamel defects in celiac disease. $J$ Oral Pathol Med 1990; 19(6): 241-245.

[5] Aguirre JM, Rodríguez R, Oribe D, Vitoria JC. Dental enamel defects in celiac patients. Oral Surg Oral Med Oral Pathol Oral Radiol Endod 1997; 84(6): 646-650.

[6] Lähteenoja H, Toivanen A, Viander M, Mäki M, Irjala K, Räihä I, Syrjänen S. Oral mucosa changes in celiac patients on a gluten-free diet. Eur J Oral Sci 1998; 106(5): 899906.

[7] Taguchi A, Tanimoto K, Suei Y, Wada T. Tooth loss and mandibular osteopenia. Oral Surg Oral Med Oral Pathol Oral Radiol Endodontol. 1995; 79(1): 127-132.

[8] Krall EA, Dawson-Hughes B, Papas A, Garcia RI. Tooth loss and skeletal bone density in healthy postmenopausal women. Osteoporos Int 1994; 4(2): 104-109.

[9] Krall EA, Garcia RI, Dawson-Hughes B. Increased risk of tooth loss is related to bone loss at the whole body, hip and spine. Calcif Tissue Int 1996; 59(6): 433-437.

[10] Taguchi A, Suei Y, Ohtsuka M, Otani K, Tanimoto K, Hollender LG. Relationship between bone mineral density and tooth loss in elderly Japanese women. Dentomaxillofac Radiol 1999; 28(4): 219-223.

[11] Von Wowern N. General and oral aspects of osteoporosis: a review. Clin Oral lnvestig 2001; 5(2): 71-82. 
[12] Nakamoto T, Taguchi A, Ohtsuka M, Suei Y, Fujita M, Tanimoto K, Tsuda M, Sanada M, Ohama K, Takahashi J, Rohlin M. Dental panoramic radiograph as a tool to detect postmenopausal women with low bone mineral density: untrained general dental practitioners' diagnostic performance. Osteoporos Int 2003; 14(8): 659-664.

[13] Engquist B, Bergendal T, Kallus T, Linden U. A retrospective multicenter evaluation of osseointegrated implants supporting overdentures. Int J Oral Maxillofacial Implants 1988; 3(2): $129-134$.

[14] Jaffin RA, Berman CL. The excessive loss of Branemark fixtures in type IV bone: a 5year analysis. $J$ Periodontol 62(1): 2-4.

[15] WHO scientific group. Prevention and management of Osteoporosis. WHO Technical Report, Series 921. Geneva. 2003.

[16] Delvin H, Horner K. Mandibular radiomorphometric indices in the diagnosis of reduced skeletal bone mineral density. Osteoporos Int 2002; 13(5): 373-378.

[17] Kribbs PJ, Chesnut CH 3rd, Ott SM, Kilcoyne RF. Relationships between mandibular and skeletal bone in an osteoporotic population. J Prosthet Dent 1989; 62(6): 703-706.

[18] Kribbs PJ, Chesnut CH 3rd, Ott SM, Kilcoyne RF. Relationships between mandibular and skeletal bone in a population of normal women. J Prosthet Dent 1990; 63(1): 86-89.

[19] White SC, Rudolph DJ. Alterations of the trabecular pattern of the jaws in patients with osteoporosis. Oral Surg Oral Med Oral Pathol Oral Radiol Endo 1999; 88(5): 628-635

[20] Klemetti E, Kolmakov S, Kröger H. Pantomography in assessment of the osteoporosis risk group. Scan J Dent Res 1994; 102(1): 68-72.

[21] Benson BW, Prihoda TJ, Glass BJ. Variations in adult cortical bone mass as measured by a panoramic mandibular index. Oral Surg Oral Med Oral Pathol 1991; 71(3): 349-356.

[22] Klemetti E, Kolmakov S, Heiskanen P, Vainio P, Lassila V. Panoramic mandibular index and bone mineral densities in postmenopausal women. Oral Surg Oral Med Oral Pathol 1993; 75(6): 774-779.

[23] Rushton VE. The role of the panoramic radiograph in the management of new patients. $\mathrm{PhD}$ dissertation, University of Manchester 2000.

[24] Taguchi A, Tanimoto K, Suei Y, Otani K, Wada T. Oral signs as indicators of possible osteoporosis in elderly women. Oral Surg Oral Med Oral Pathol Oral Radiol Endod 1995; 80(5): 612-616.

[25] Law AN, Bollen AM, Chen SK. Detecting osteoporosis using dental radiographs: a comparison of four methods. J Am Dent Assoc 1996; 127(12): 1734-1742.

[26] Horner K, Devlin H, Alsop CW, Hodgkinson IM, Adams JE. Mandibular bone mineral density as a predictor of skeletal osteoporosis. Br J Radiol 1996; 69(827): 1019-1025.

[27] McNeish AS, Harms HK, Rey J, Shmerling DH, Visakorpi JK, Walker-Smith JA. The diagnosis of coeliac disease. A commentary on the current practices of members of the European Society for Pediatric Gastroenterology and Nutrition (ESPGAN). Arch Dis Child 1979; 54(10): 783-786.

[28] Dervis E. Oral implications of osteoporosis. Oral Surg Oral Med Oral Pathol Oral Radiol Endod 2005; 100(3): 349-356.

[29] Ledgerton D, Horner K, Devlin H, Worthington H. Radiomorphometric indices of the mandible in a British female population. Dentomaxillofac Radiol 1999; 28(3): 173-181.

[30] Benson BW, Prihoda YJ, Glass BJ. Variations in adult cortical bone mass as measured by a panoramic index. Oral Surg Oral Med Oral Pathol 1991; 71(3): 394-356. 
[31] Horner K, Develin H, Harvey L. Detecting patients with low skeletal bone mass. J Dent 2002; 30(4): 171-157.

[32] Devlin H, Karayianni K, Mitsea A, Jacobs R, Lindh C, van der Stelt P, Marjanovic E, Adams J, Pavitt S, Horner K. Diagnosing osteoporosis by using dental panoramic radiographs: the OSTEODENT project. Oral Surg Oral Med Oral Pathol Oral Radiol Endod 2007; 104(6): 821-828.

[33] Norusis MJ. SPSS PC+ V2.0 Base Manual. SPSS, Chicago, 1988.

[34] Lee BD, White SC. Age and trabecular features of alveolar bone associated with osteoporosis. Oral Surg Oral Med Oral Pathol Oral Radiol Endod. 2005; 100(1): 92-98.

[35] McFarlene XA, Bhalla AK, Reeves DE, Morgan LM, Robertson DA. Osteoporosis in treated adult coeliac disease. Gut 1995; 36(5): 710-714.

[36] Licks R, Licks V, Ourique F, Radke Bittencourt H, Fontanella V. Development of a prediction tool for low bone mass based on clinical data and periapical radiography. Dentomaxillofac Radiol 2010; 39(4): 224-230.

[37] Lindh E, Ljunghall S, Larsson K, Lavo B. Screening for antibodies against gliadin in patients with osteoporosis. J Intern Med 1992; 231(4): 403-406.

[38] Ciacci C, Cirillo M, Mellone M, Basile F, Mazzacca G, De Santo NG. Hypocalciuria in overt and subclinical celiac disease. Am J Gastroenterol 1995; 90(9): 1480-1484.

[39] Molteni N, Bardella M, Vezzoli G, Pozzoli E, Bianchi D. Intestinal calcium absorption as shown by stable strontium test in celiac disease before and after gluten-free diet. Am J Gastroenterol 1995; 90(11): 2025-2028.

[40] Keaveny AP, Freaney R, McKenna MJ, Masterson J, O'Donoghue DP. Bone remodeling indices and secondary hyperparathyroidism in celiac disease. $A m J$ Gastroenterol 1996; 91(6): 1226-1231.

[41] Smecuol E, Mauriño E, Vazquez H, Pedreira S, Niveloni S, Mazure R, Boerr L, Bai JC. Gynaecological and obstetric disorders in celiac disease: frequent clinical onset during pregnancy or the puerperium. Eur J Gastroenterol Hepatol 1996; 8(1): 63-89.

[42] Watts NB. Fundamentals and pitfalls of bone densitometry using dual-energy X-ray absorptiometry (DXA). Osteoporos Int 2004; 15(11): 847-854.

[43] Kribbs PJ, Chesnut CH 3rd, Ott SM, Kilcoyne RF. Relationship between mandibular and skeletal bone in an osteoporotic population. J Prosthet Dent 1989; 62(6): 703-707.

[44] Horner K, Devlin H, Alsop CW, Hodgkinson M, Adams JE. Mandibular bone mineral density as a predictor of skeletal osteoporosis. Br J Radiol 1996; 69(827): 1019-1025.

[45] Bollen AM, Taguchi A, Hujoel PP, Hollender LG. Case-control study on self-reported osteoporotic fractures and mandibular cortical bone. Oral Surg Oral Med Oral Pathol Oral Radiol Endod 2000; 90(4): 518-524.

[46] Yaşar F, Akgünlï F. The differences in panoramic mandibular indices and fractal dimension between patients with and without spinal osteoporosis. Dentomaxillofac Radiol 2006; 35(1): 1-9.

[47] Mohajery M, Brooks SL. Oral radiographs in the detection of early signs of osteoporosis. Oral Surg Oral Med Oral Pathol 1992; 73(1): 112-117.

[48] Taguchi A, Tsuda M, Ohtsuka M, Kodama I, Sanada M, Nakamoto T, Inagaki K, Noguchi T, Kudo Y, Suei Y, Tanimoto K, Bollen AM. Use of dental panoramic radiographs in identifying younger postmenopausal women with osteoporosis. Osteoporos Int 2006; 17(3): 387-394. 
[49] Ardakani FE, Niafar N. Evaluation of changes in the mandibular angular cortex using panoramic images. J Contemp Dent Pract 2004; 5(3): 1-15.

[50] [No authors listed]. Osteoporosis: review of the evidence for prevention, diagnosis and treatment and cost-effectiveness analysis. Osteoporos Int 1998; 8(Suppl. 4): S7-80.

[51] Lee BD, White SC. Age and trabecular features of alveolar bone associated with osteoporosis. Oral Surg Oral Med Oral Pathol Oral Radiol Endodon 2005; 100(1): 9298.

[52] Shrout MK, Hildebolt CF, Potter BJ, Brunsden TK, Pilgram TK, Dotson M, Yokoyama-Crothers N, Hauser J, Cohen S, Kardaris E, Civitelli R, Hanes P. Comparison of morphological measurements extracted from digitized dental radiographs with lumbar and femoral bone mineral density measurements in postmenopausal women. $J$ Periodontol 2000; 71(3): 335-340.

[53] Von Wowern N. Microradiographic and histomorphometric indices of mandibles for diagnosis of osteopenia. Scand J Dent Res 1982; 90(1): 47-63.

[54] Güngör K, Akarslan Z, Akdevelioglu M, Erten H, Semiz M. The precision of the panoramic mandibular index. Dentomaxillaofac Radiol 2006; 35(6): 442-446. 
استخدام قياسات الأشعة البانور امية لعظام القك السفلي كمؤشر محتمل لحدوث هشاشة العظام عند مرضى اضطر ابات الجهاز الهضدي (مرض سيليك)

هثام إبراهيم عثمان ، و سليمان عمرو عوده

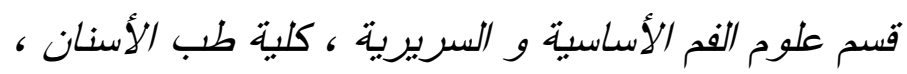
جامعة الملك عبد العزبيز جلة - المدلكة العربية السعودية

الستتخص. الغرض من هذا البحث هو استخدام قياسات الأشعة

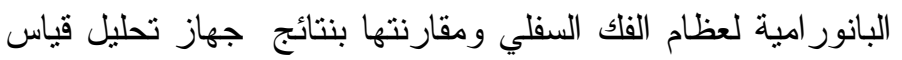

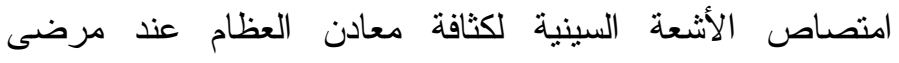

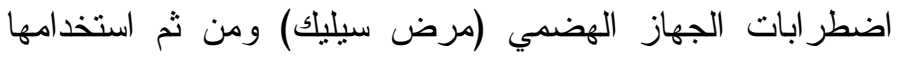
كمؤشر محتمل لحدوث مرض هشانشة العظام. اختير في هذا البحث

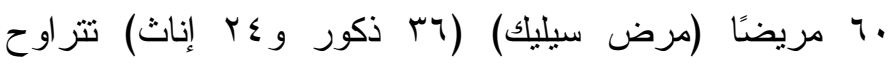

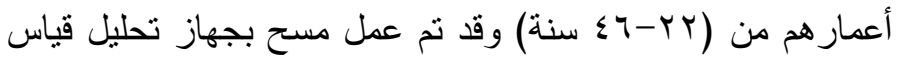

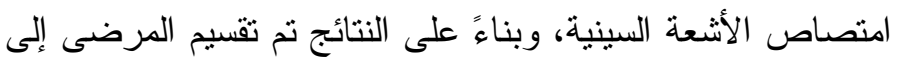

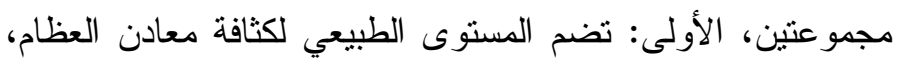

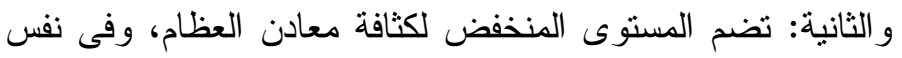

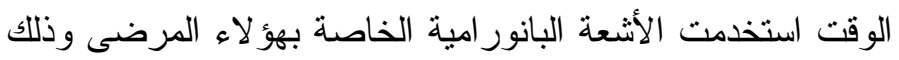

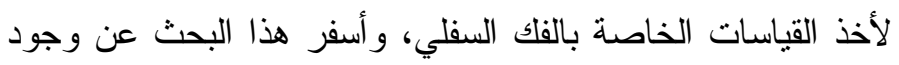

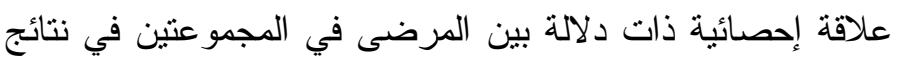

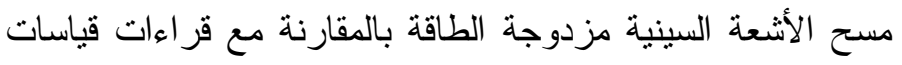

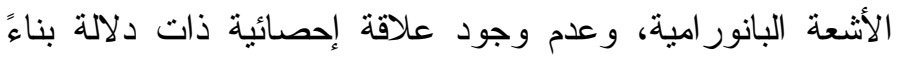
على جنس المرضى في المجمو عتين. 
بستتبط من هذا البحث إمكانية استخدام قياسات الأشعة

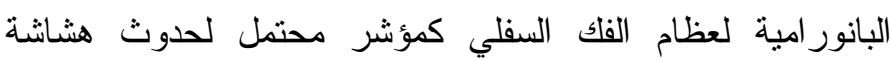

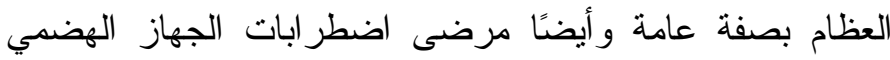

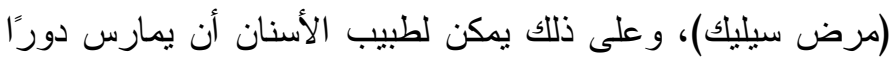

مهمًا في النتخيص المبدئي لمرض هشائنة العظام. 